\title{
An Event-related Potential Study of Error-monitoring Deficits in Female College Students Who Participate in Binge Drinking
}

\author{
Eun-Hui Kim, Myung-Sun Kim \\ Department of Psychology, Sungshin Women's University, Seoul, Korea
}

\begin{abstract}
Objective: This study investigated error-monitoring deficits in female college students with binge drinking (BD) using event-related potentials (ERPs) and the modified Flanker task.

Methods: Participants were categorized into BD $(n=25)$ and non-BD $(n=25)$ groups based on the scores of the Korean-version of the Alcohol Use Disorder Identification Test (AUDIT-K) and the Alcohol Use Questionnaire (AUQ). The modified Flanker task, consisting of congruent (target and flanker stimuli are the same) and incongruent (target and flanker stimuli are different) conditions, was used to evaluate error-monitoring abilities.

Results: The BD group exhibited significantly shorter response times and more error rates on the Flanker task, as well as reduced error-related negativity (ERN) amplitudes compared with the non-BD group. Additionally, ERN amplitudes measured at $\mathrm{FCz}$ and $\mathrm{Cz}$ were significantly correlated with scores on the AUDIT-K and AUQ in the whole participants. The $\mathrm{BD}$ and non-BD groups did not show any significant differences in error positivity amplitudes.

Conclusion: The present results indicate that college students with BD have deficits in error-monitoring, and that reduced ERN amplitudes may serve as a biological marker or risk factor of alcohol use disorder.
\end{abstract}

KEY WORDS: Alcohol drinking; Error positivity; Error negativity; Event-related potentials; Inhibition; Young adult.

\section{INTRODUCTION}

Binge drinking (BD), a pattern of excessive alcohol consumption followed by a period of abstinence, is defined on the basis of the quantity, frequency and speed of alcohol consumption. ${ }^{1,2)} \mathrm{BD}$ has recently gained attention as a major health problem, particularly in college students, because $\mathrm{BD}$ is most prevalent among this population, ${ }^{3,4)}$ causes serious academic and interpersonal problems, and increases the likelihood of developing alcohol use disorder (AUD), ${ }^{6,7)}$ Patients with AUD and individuals participating in BD share common abnormalities in brain structure/function and neuropsychological function. ${ }^{8,9)}$ For example, structural/functional abnormalities in hippocampus and prefrontal cortex, ${ }^{10,11)}$ and executive dys-

Received: September 13, 2017 / Revised: January 2, 2018

Accepted: January 23, 2018

Address for correspondence: Myung-Sun Kim, PhD

Department of Psychology, Sungshin Women's University, 2

Bomun-ro 34da-gil, Seongbuk-gu, Seoul 02844, Korea

Tel: +82-2-920-7592, Fax: +82-2-920-2040

E-mail: kimms@sungshin.ac.kr

ORCID: http://orcid.org/0000-0003-3520-1112 functions, including working memory, ${ }^{12)}$ planning, ${ }^{13)}$ attention, ${ }^{14)}$ inhibition, ${ }^{15)}$ are observed both in $\mathrm{BD}$ and AUD.

Individuals with AUD are characterized by the inability to inhibit drinking behavior ${ }^{16)}$ and failure to learn from previous harmful behavior. ${ }^{17)}$ In other words, these individuals have deficits in self-control. Error-monitoring, an ability to monitor one's own behavior, including error detection and adjustment of one's behavior for the intended purposes, ${ }^{18,19)}$ is a fundamental psychological process to self-control behavior. Therefore, impaired error-monitoring could result in failure to monitor excessive alcohol intake and to correct or adjust drinking behavior after slips, which, in turn, lead to the development of AUD. ${ }^{17,20)}$ Deficits in error-monitoring are observed in patients with $A \cup D^{211}$ and young heavy drinkers. ${ }^{20,22,23)}$

Neuroimaging studies have provided the neurological substrates underlying deficits in error-monitoring observed in patients with AUD or individuals who drink heavily. The anterior cingulate cortex (ACC) and dorsolateral prefrontal cortex are involved in error-monitoring. ${ }^{19,24,25)}$ The prefrontal cortex is particularly vulner-

(ㄷ) This is an Open-Access article distributed under the terms of the Creative Commons Attribution Non-Commercial License (http://creativecommons.org/licenses/by-nc/4.0) which permits unrestricted non-commercial use, distribution, and reproduction in any medium, provided the original work is properly cited. 
able to alcohol, ${ }^{26-28)}$ and structural abnormalities and dysfunctions in the prefrontal cortex and ACC are observed in patients with AUD and individuals with BD. For example, reduced prefrontal cortex volume ${ }^{29)}$ and blood flow to the prefrontal cortex $^{30)}$ are observed in patients with AUD. In addition, reduced thickness of the $\mathrm{ACC}^{31)}$ and prefrontal activation $^{32)}$ are observed in individuals with $\mathrm{BD}$, whereas reduced ACC volume is observed in adolescent heavy drinkers. ${ }^{33)}$

Although neuroimaging studies have contributed to revealing the brain structures involved in error-monitoring, they provide little information regarding sequential activations of brain areas involved in error-monitoring. Due to the high temporal resolution, event-related potentials (ERPs) are widely used to investigate cognitive functions. ${ }^{34)}$ ERPs are particularly useful for measuring error-monitoring, which is elicited rapidly in a very short period. ${ }^{35,36)}$

Studies that have investigated error-monitoring using ERPs have consistently reported error-related negativity $(E R N)$ and error positivity $(\mathrm{Pe})$ as electrophysiological indices of error-monitoring. ERN is a negative peak observed 50 to $150 \mathrm{~ms}$ after incorrect responses, whereas $\mathrm{Pe}$, a positive peak occurring after ERN, is observed 150 to $400 \mathrm{~ms}$ after erroneous response. ${ }^{37-40)}$ ERN and Pe reflect different stages of error processing. ${ }^{41)}$ Previous studies suggested that ERN reflects initial and automatic error detection ${ }^{42)}$ or the magnitude of the individual's responses to his/her own errors. ${ }^{38)}$ Although the functional significance of Pe is less understood than ERN, ${ }^{41)}$ it has been suggested that Pe reflects the conscious awareness of errors ${ }^{41,43)}$ and the motivation to correct the errors, ${ }^{44)}$ because greater Pe amplitudes are observed after consciously recognized errors than after unrecognized errors. ${ }^{45,46)}$

Previous studies which investigated the effect of alcohol on error-monitoring using ERPs have reported that normal participants who consume alcohol exhibit reduced ERN and Pe amplitudes ${ }^{47,48)}$ or only reduced ERN amplitudes ${ }^{44)}$ compared with those who do not consume alcohol. Young heavy drinkers also show reduced ERN amplitudes ${ }^{22,23)}$ or reduced Pe amplitudes ${ }^{49)}$ compared with those who do not regularly drink heavily. In contrast, Smith et al. ${ }^{20)}$ reported increased ERN amplitudes in female but not in male heavy drinkers compared with controls, resulting in overall non-significant ERN amplitudes between heavy drinkers and controls. Schellekens et al. ${ }^{50)}$ reported increased ERN amplitudes in patients with AUD, particularly in those with a comorbid anxiety disorder, compared with controls. In addition, Smith et al..$^{511}$ did not observe significant differences in ERN or Pe amplitudes between young heavy drinkers and controls. These inconsistent findings suggest that alcohol consumption affects error-monitoring differently depending on gender and anxiety comorbidity.

The Flanker task is widely used to measure error-monitoring ${ }^{52,53)}$ because this task elicits errors by manipulating the level of difficulty. ${ }^{54)}$ In the Flanker task, it is required for participants to attend to a target stimulus presented in the center, while ignoring the flanker stimuli presented to the right and left of the target stimulus. The Flanker task consists of congruent condition, under which the target and flanker stimulus figures are the same, and incongruent condition, under which the target and flanker stimulus figures differ. A longer response time and more errors are observed under the incongruent condition than the congruent condition, which is called the Flanker congruency effect. ${ }^{52,55)}$ Normal individuals who consume alcohol exhibit increased response time and decreased accuracy on the Flanker task than those who do not consume alcohol. ${ }^{56)}$

Although a few recent studies have investigated error-monitoring using ERPs in young heavy drinkers who were selected based on the quantity of alcohol consumption $^{20,22,23,511}$ no study had investigated error-monitoring ability in college students with BD using ERPs. Females who participate in $\mathrm{BD}$ exhibit more impaired functions than BD males, ${ }^{57,58)}$ and different performance patterns are observed on an error-monitoring task depending on gender ${ }^{20)}$ and anxiety disorder comorbidity. ${ }^{50)}$ These results indicate that gender differences should be considered in BD studies.

Given this background, we investigated error-monitoring ability in female college students who participated in BD using ERPs and the modified Flanker task while controlling for anxiety and depression. We hypothesized that college students with BD would have error-monitoring deficits that would be reflected by poorer performances on the Flanker task and smaller ERN and/or Pe amplitudes than those who did not participate in BD. 


\section{METHODS}

\section{Participants}

We administered the Korean version of the Alcohol Use Disorder Identification Test (AUDIT-K) $)^{59,60)}$ and the Alcohol Use Questionnaire (AUQ) ${ }^{611}$ to 250 female college students through webhard. BD was defined on the basis of the quantity, frequency and speed of alcohol consumption; drink 5 (male) or 4 (female) glasses more than once during the previous 2 weeks ${ }^{1)}$ and drink 3 (male) or 2 (female) glasses per hour. ${ }^{2}$

The World Health Organization recommends a score of $>8$ on the AUDIT as a cut-off ${ }^{59)}$; however, others have suggested that the sensitivity and specificity for the problem drinking are highest when a score of 12 on the AUDIT is used as cut-off. ${ }^{60,61)}$ Additionally, a score of $>26$ on the AUDIT indicates the possibility of alcohol dependence. ${ }^{62)}$

Therefore, in this study, those who obtained total scores of 12 to 26 on the AUDIT, drank four glasses more than once during the previous 2 weeks, and drank more than two glasses per hour (measured by AUQ item 10), were included in the BD group. Those who obtained total scores $<8$ on the AUDIT, did not drink four glasses during the last 2 weeks, and drank less than one glass per hour, were included in the non-BD group. One glass contains approximately 12 -g ethanol.

We administered the Structured Clinical Interview for DSM-IV Axis I disorder, research version, non-patient edition (SCID-I-NP) ${ }^{63)}$ to ensure that no participant had psychiatric or neurological disorders. Parents' alcohol use can affect their offspring's alcohol use. ${ }^{64)}$ Therefore, the Children of Alcoholics Screening Test (CAST) ${ }^{65)}$ was administered to identify whether the participants' parents had a history of AUD, and those who obtained a score $>6$ on the CAST were excluded.

The intelligence level of participants was evaluated by the Korean version of the Wechsler Adult Intelligence Scale. ${ }^{66)}$ The Self-Rating Depression Scale $(\mathrm{SDS})^{67)}$ and the State-Trait Anxiety Inventory (STAI) ${ }^{68)}$ were used to evaluate depression and anxiety, respectively.

Forty-two and forty students were satisfied with the criteria for $\mathrm{BD}$ and non-BD, respectively. However, those with left-handedness, ambidexterity and history of psychiatric disorders were excluded, and finally 25 students each were included in the BD and non-BD groups. All participants were instructed to abstain from using alcohol for 48 hours prior to the experiment. This study was approved by the Institutional Bioethics Review Board of Sungshin Women's University (No. SSWUIRB2015-060). All participants provided written informed consent after receiving a complete description of the study, and they were paid for their participation.

\section{Alcohol Use Disorder Identification Test}

The AUDIT ${ }^{59)}$ is a 10-item self-administered questionnaire that is used to measure the quantity and frequency of alcohol consumption, the presence of alcohol dependence, and psychosocial problems related to alcohol consumption.

\section{Alcohol Use Questionnaire}

In this study, items 10,11 , and 12 of the AUQ were used to evaluate the speed of drinking (average drinks per hour), number of times binge drunk in the previous 6 months, and percentage of times getting drunk when drinking, respectively. ${ }^{61)}$ Additionally, the binge score was calculated as [ $4 \times($ Item 10)+Item $11+0.2 \times($ Item 12)] in order to estimate the severity of $\mathrm{BD} .{ }^{69)}$

\section{The Flanker Task}

The modified Flanker task ${ }^{70)}$ was developed to compensate for the low level of difficulty of the original Flanker task and to measure error-monitoring. The stimuli were presented on the computer monitor (Fig. 1A), and a response panel containing buttons designated to the direction of the target stimulus was placed in front of the monitor (Fig. 1B).

Four types of triangles indicating up/down and left/right directions were used as target stimuli, and the participants were required to press the button designated to the direction of the target stimulus as rapidly and accurately as possible. The target stimulus was presented in the center on a monitor, and the flanker stimuli were presented to the left/right of the target stimulus. In a congruent condition, the directions of the target and flanker stimuli were the same (Fig. 2A), whereas the directions of the target and flanker stimuli were different in an incongruent condition (Fig. 2B).

In this study, each triangle produced one congruent and three incongruent conditions. More errors and reduced ERN amplitudes are observed in the incongruent condition than the congruent condition. ${ }^{70)}$ Thus, in this 

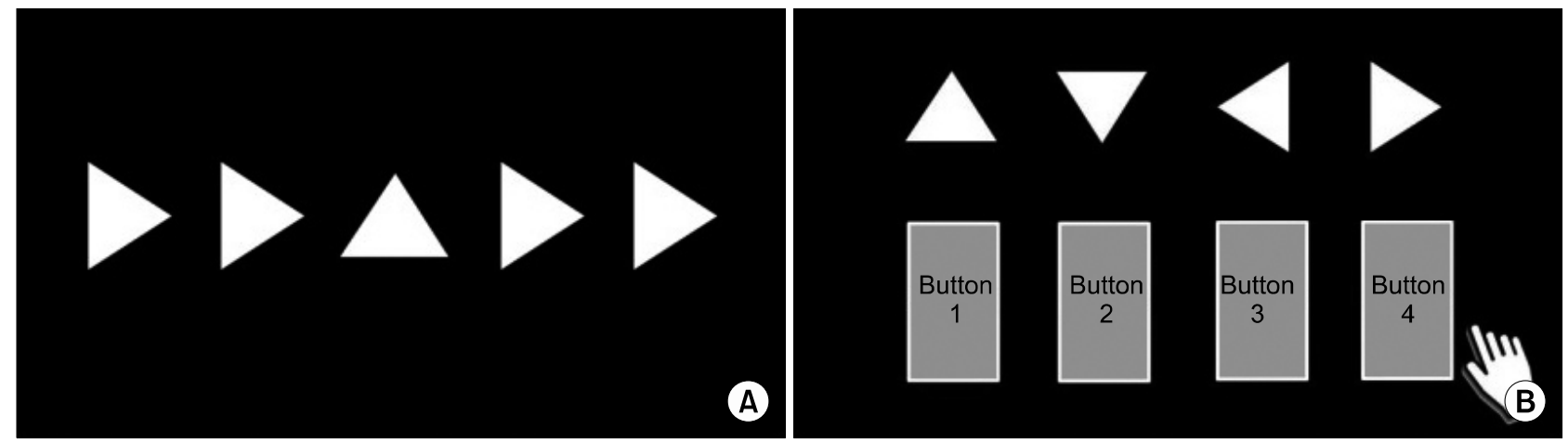

Fig. 1. (A) The Flanker task consists of one target stimulus (center) and four flanker stimuli (left/right of the target stimulus). The stimuli are presented on the computer monitor. (B) The response panel containing response buttons designated for the direction of the target stimulus is placed in front of the computer monitor. Participants are instructed to press one of four buttons designated for the direction of the target stimulus.
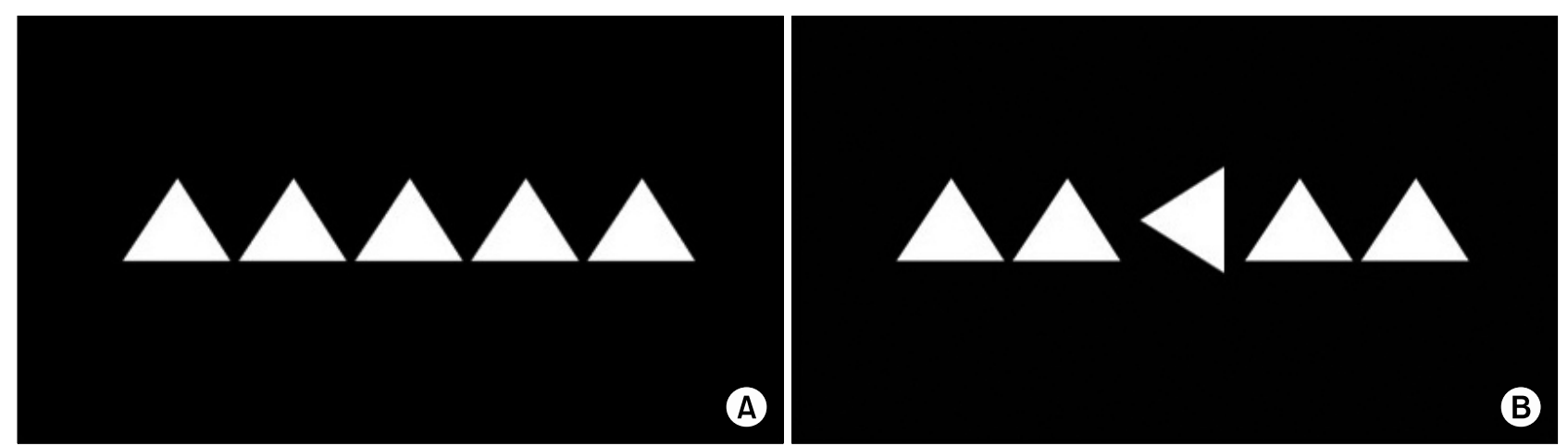

Fig. 2. The Flanker task condition. (A) In the congruent condition, the directions of target stimulus and flanker stimuli are same. (B) In the incongruent condition, the directions of target stimulus and flanker stimuli are different.

study, congruent and incongruent conditions were presented at the rate of $4: 6$. In other words, we presented incongruent conditions more frequently than congruent conditions to adjust the level of difficulty. A total of 800 trials (320 congruent conditions and 480 incongruent conditions) were administered randomly in four blocks and the location of the response button designated to the target stimulus was changed across the blocks.

The crosshair was displayed for $700 \mathrm{~ms}$, then the stimuli were presented for $80 \mathrm{~ms}$ followed by 1,200-ms response time. The inter-stimulus interval was 1,980 ms. E-PRIME (Psychological Software Tools Inc., Sharpsburg, PA, USA) was used for these operations. A block of 60 trials was administered to ensure that all participants understood the instructions prior to the experimental session. The procedure of the Flanker task is presented in Figure 3.

\section{Electrophysiological Recording Procedure}

A 64-channel HydroCel Geodesic Sensor Net con- nected to a 64-channel, high-input impedance amplifier (Net Amp 300; Electrical Geodesics, Eugene, OR, USA) was used to record electroencephalographic (EEG) activity in an electrically shielded and soundproofed experimental room. All of the electrodes were referenced to $\mathrm{Cz}$, and eye movements and blinks were monitored by electrodes positioned near the outer canthus and beneath the left eye. Impedance was maintained at $50 \mathrm{k} \Omega$ or less. ${ }^{71)}$

EEG was recorded continuously using a 0.1 to $100 \mathrm{~Hz}$ analog bandpass and a sampling rate of $500 \mathrm{~Hz}$ during the experiment. After data collection, the EEG measured in the congruent and incongruent conditions was segmented into $600 \mathrm{~ms}$ epochs (including a $100 \mathrm{~ms}$ pre-response baseline). The epochs was baseline-corrected, and those contaminated by artifacts were rejected prior to averaging (the threshold for artifact rejection was a peakto-peak amplitude of $\pm 70 \mu \mathrm{V}$ ). All data associated with incorrect responses were averaged with an average-reference transformation, and the ERPs were digitally low-pass 


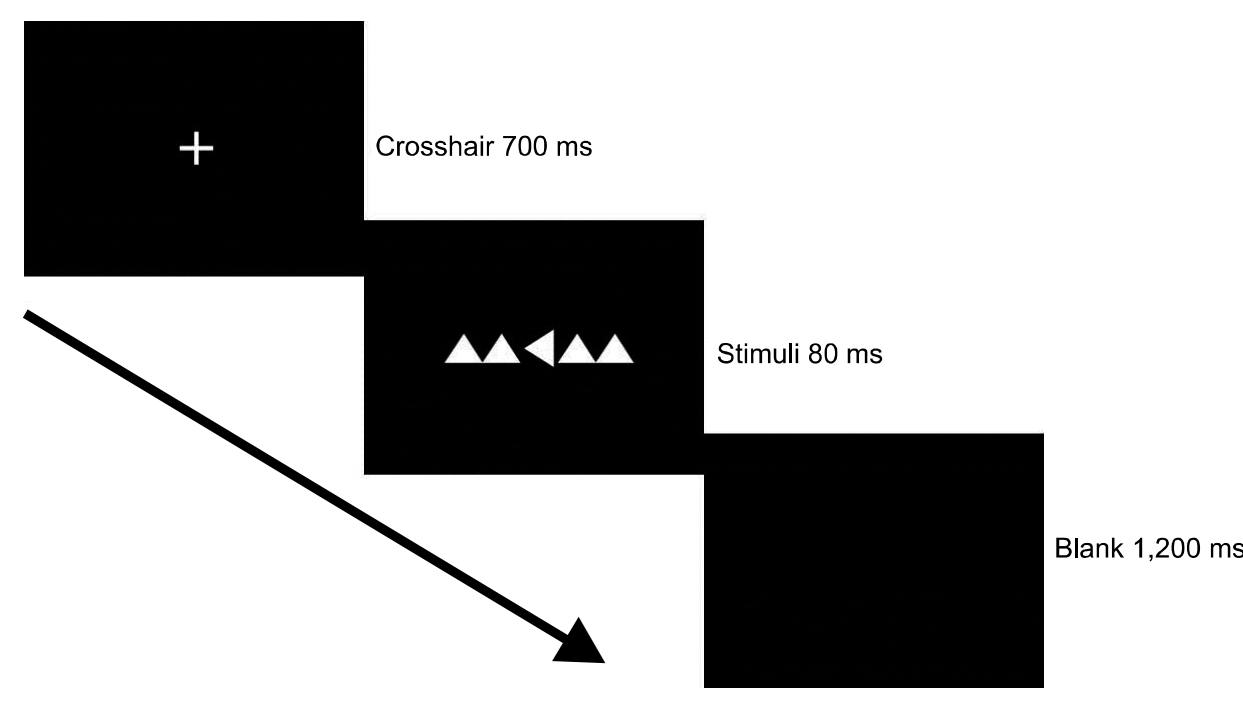

Fig. 3. The procedure of the Flanker task.

filtered at $30 \mathrm{~Hz}$. The mean numbers of trials included in the ERN/Pe analysis for the BD and non-BD groups were 72.36 (standard deviation [SD], 10.31) and 42.72 (SD, 8.37), respectively. The two groups differed in terms of trials for averaging ERN/Pe $(t[48]=3.09, p<0.01)$, as the BD group committed more errors on the Flanker task than did the non-BD group.

\section{Statistical Analysis}

Based on visual inspections of the grand-averaged (Fig. 4) and individual ERP waveforms, the ERN and Pe time windows were determined. ERN was defined as the most negative peak in a 50 to $150 \mathrm{~ms}$ period after onset of erroneous responses, whereas $\mathrm{Pe}$ as the most positive peak in a 150 to $400 \mathrm{~ms}$ period after the onset of erroneous responses. Separate mixed-design repeated measures analysis of variance (ANOVA) was used to analyze the amplitudes and latencies of ERN and Pe. The electrode site (F3, Fz, F4, FC3, FCz, FC4, C3, Cz, C4, P3, Pz, and P4) was a within-subject factor and group (BD and non-BD groups) was a between-subjects factor. Green-Geisser corrections were utilized for violations of sphericity, and the corrected $p$ values are reported when appropriate. The relationships between ERN/Pe amplitudes and scores on the BD measures were analyzed by Pearson's product-moment correlation analysis. Demographic characteristics were analyzed by the independent $t$ test, and the behavioral performances of the Flanker task were analyzed by mixed design ANOVA, using condition as a within-subject factor (congruent and incongruent conditions) and group as a between-subject factor.
Statistical analyses were carried out with SPSS version 20 for Windows (IBM Corp., Armonk, NY, USA).

\section{RESULTS}

\section{Demographic Characteristics}

The BD and non-BD groups did not differ in terms of age $(t[48]=-0.45$, not significant [ns]), educational level $(t[48]=-0.85, \mathrm{~ns})$, intelligence quotient $(t[48]=0.17, \mathrm{~ns})$, SDS $(t[48]=0.88, n s)$, state anxiety on the STAI $(t[48]=$ 0.42 , ns), or trait anxiety on the STAI $(t[48]=0.90$, ns). However, the BD group showed significantly higher total AUDIT-K score $(t[48]=19.20, p<0.001)$, drinking speed $(t[48]=10.42, p<0.001)$, number of times being drunk in the previous 6 months $(t[48]=3.67, p<0.01)$, percentage of times getting drunk when drinking $(t[48]=3.82, p<$ $0.001)$, and binge score on the AUQ $(t[48]=8.06, p<$ $0.001)$ than those in the non-BD group. The demographic characteristics of the two groups are presented in Table 1.

\section{Behavioral Performance on the Flanker Task}

The statistical analysis of error rates showed the main effects of group $(\mathrm{F}[1,48]=10.27, p<0.001)$ and condition $(\mathrm{F}[1,48]=49.68, p<0.001)$. The BD group exhibited significantly higher error rates than did the non-BD group, and more errors were elicited in the incongruent condition than the congruent condition. In addition, an interaction effect was detected for group $\times$ condition ( $F[1,48]=$ $5.39, p<0.05)$. The BD group showed significantly higher error rates in congruent $(\mathrm{F}[1,48]=7.44, p<0.05)$ and incongruent conditions $(\mathrm{F}[1,48]=11.06, p<0.05)$ than 
$\mathrm{Fz}$

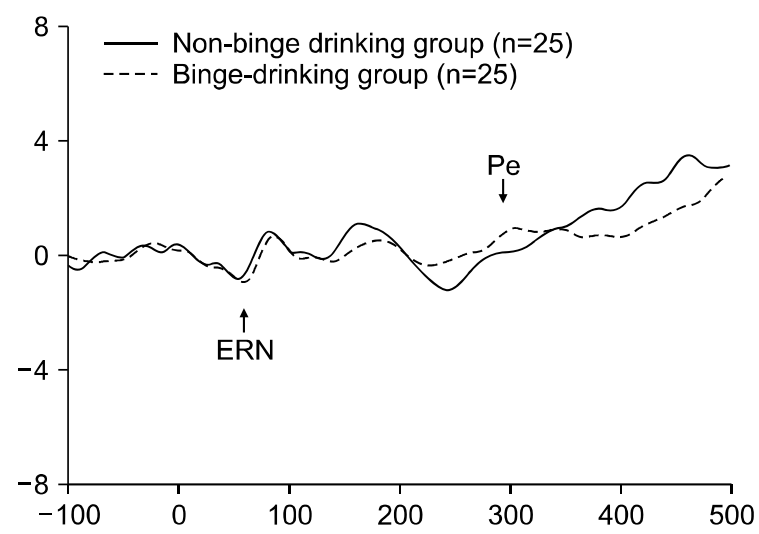

$\mathrm{Cz}$

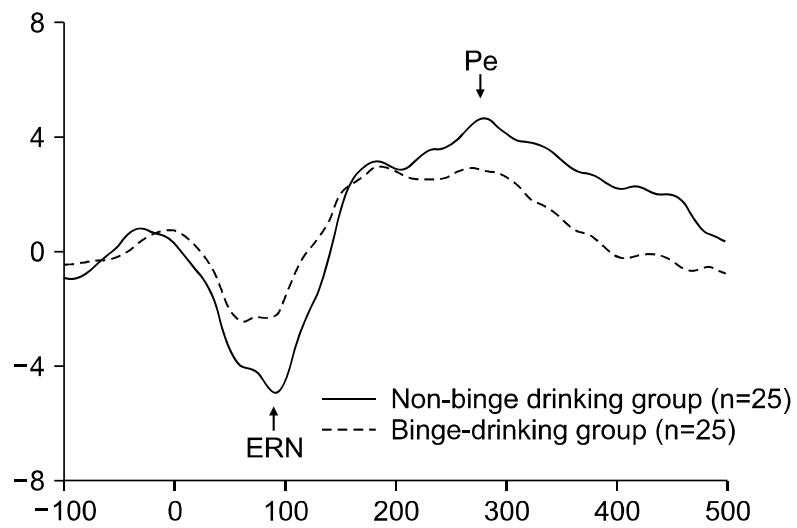

$\mathrm{FCz}$

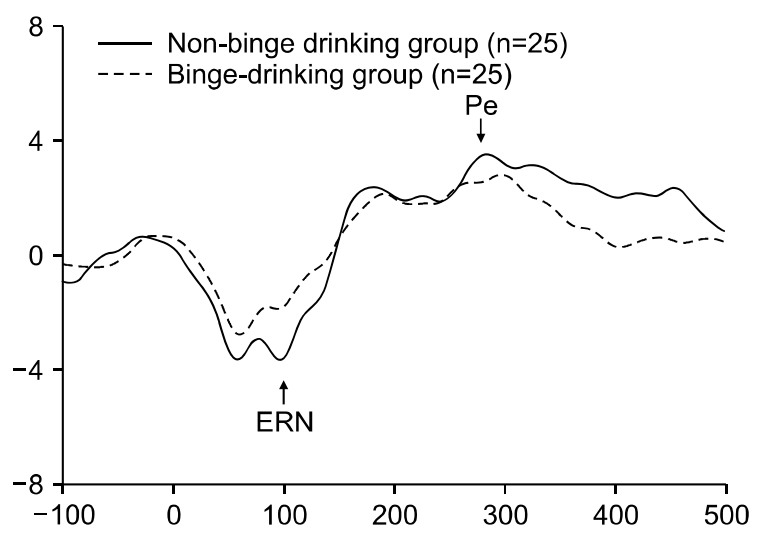

$\mathrm{Pz}$

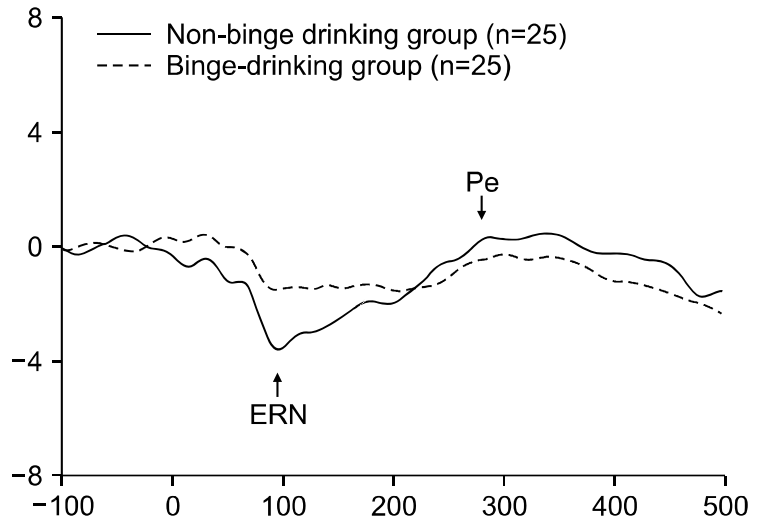

Fig. 4. The grand-averaged event-related potentials elicited by erroneous responses at $\mathrm{Fz}, \mathrm{FCz}, \mathrm{Cz}$, and $\mathrm{Pz}$ for non-binge drinking and bingedrinking groups.

Pe, error positivity; ERN, error-related negativity.

Table 1. Demographic characteristics of non-binge drinking and binge-drinking groups

\begin{tabular}{lccc}
\hline \multicolumn{1}{c}{ Chracteristic } & Non-binge drinking $(\mathrm{n}=25)$ & Binge-drinking $(\mathrm{n}=25)$ & $t$ \\
\hline Age $(\mathrm{yr})$ & $21.72 \pm 2.44$ & $21.44 \pm 1.89$ & -0.45 \\
Education $(\mathrm{yr})$ & $15.20 \pm 1.32$ & $14.92 \pm 1.00$ & -0.85 \\
IQ & $114.40 \pm 7.05$ & $114.76 \pm 7.64$ & 0.17 \\
SDS & $41.76 \pm 7.32$ & $43.52 \pm 6.68$ & 0.88 \\
STAl state & $42.08 \pm 9.21$ & $43.28 \pm 11.00$ & 0.42 \\
STAI trait & $43.36 \pm 9.23$ & $45.76 \pm 9.71$ & 0.90 \\
AUDIT-K & $1.68 \pm 2.06$ & $19.04 \pm 4.03$ & $19.20^{* * *}$ \\
Speed of drinking (drinks/hr) & $0.84 \pm 0.55$ & $4.24 \pm 4.54$ & $10.42^{* * *}$ \\
Times drunk in the last 6 months & $0.16 \pm 0.47$ & $9.80 \pm 13.14$ & $3.67^{* *}$ \\
Percentage of times became drunk when drinking & $18.00 \pm 33.88$ & $53.48 \pm 31.80$ & $3.82^{* * *}$ \\
AUQ binge drinking score & $7.12 \pm 6.80$ & $37.92 \pm 17.86$ & $8.06^{* * *}$ \\
\hline
\end{tabular}

Values are presented as mean \pm standard deviation.

IQ, intelligence quotient; SDS, Self-Rating Dpression Scale; STAI, Spieberger's State-Trait Anxiety Inventory; AUDIT-K, The Korean version of Alcohol Use Disorder Identify Test; AUQ, Alcohol Use Questionnaire.

${ }^{* *} p<0.01,{ }^{* * *} p<0.001$.

those in the non-BD group.

The main effects of group $(\mathrm{F}[1,48]=8.23, p<0.01)$ and condition $(F[1,48]=200.66, p<0.001)$, were observed for response time. The BD group showed significantly shorter response times than those of the non-BD group in the congruent $(F[1,48]=9.07, p<0.01)$ and congruent conditions 
Table 2. Mean error rate and response time in non-binge drinking and binge-drinking groups

\begin{tabular}{lccccc} 
& \multicolumn{2}{c}{ Non-binge drinking $(\mathrm{n}=25)$} & & \multicolumn{2}{c}{ Binge-drinking $(\mathrm{n}=25)$} \\
\cline { 2 - 3 } \cline { 5 - 6 } & Congruent & Incongruent & & Congruent & Incongruent \\
\hline Error rate $(\%)$ & $6.08 \pm 4.05$ & $8.28 \pm 4.66$ & & $9.44 \pm 4.64$ & $13.80 \pm 6.87$ \\
Response time $(\mathrm{ms})$ & $533.23 \pm 68.64$ & $564.44 \pm 72.62$ & & $481.63 \pm 66.80$ & $507.23 \pm 61.19$ \\
\hline
\end{tabular}

Values are presented as mean \pm standard deviation.

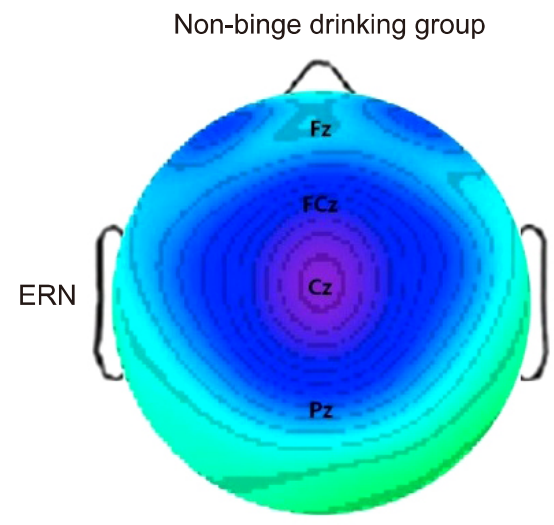

$95 \mathrm{~ms}$

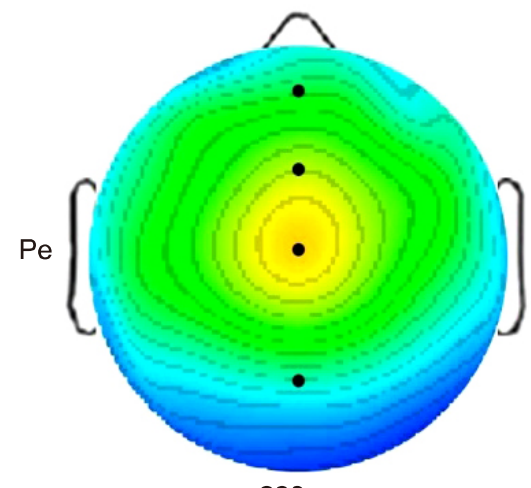

$280 \mathrm{~ms}$

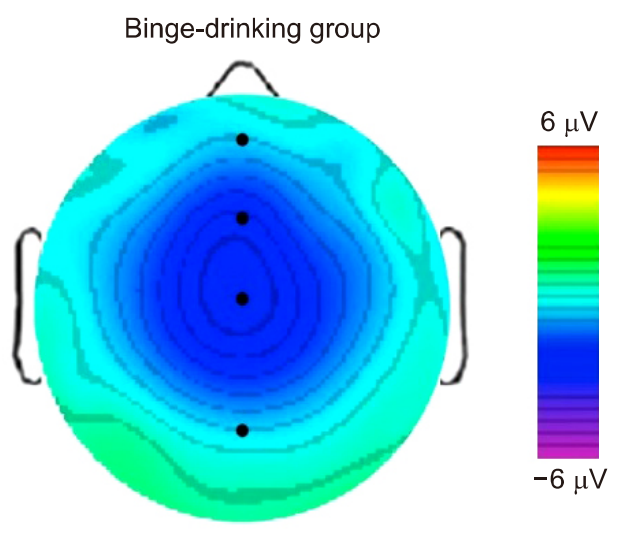

$95 \mathrm{~ms}$

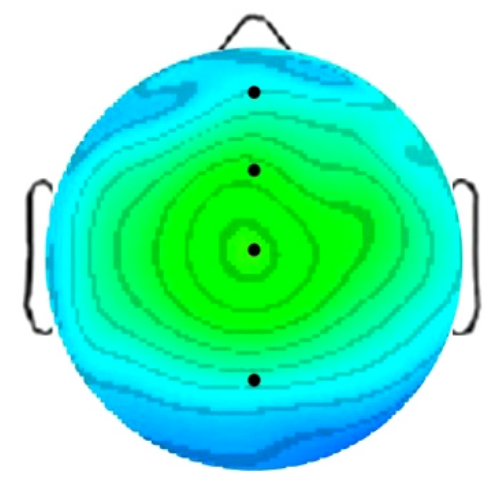

$280 \mathrm{~ms}$

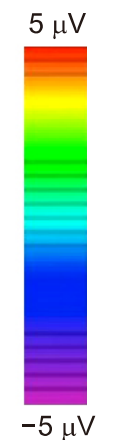

$-5 \mu \mathrm{V}$

Fig. 5. Topographical distributions of error-related negativity (ERN) and error positivity (Pe) elicited by erroneous responses for non-binge and binge-drinking groups.

$(\mathrm{F}[1,48]=7.25, p<0.05)$. The response time elicited by the incongruent condition was significantly longer than the response time elicited by the congruent condition. No interaction effect of groupxcondition was observed $(F[1,48]=1.96$, ns). The mean error rates and response times of the BD and non-BD groups are presented in Table 2.

\section{Electrophysiological Measures}

The grand-averaged ERPs elicited by erroneous responses at midline sites ( $F z, F C z, C z$, and $\mathrm{Pz}$ ) were displayed in Figure 4. Both the BD and non-BD groups exhibited ERN and Pe; however, BD group showed smaller ERN amplitudes, particularly at the $\mathrm{Cz}$ site, than did the non-BD group. The topographical distributions in elec- trical activity measured at all electrode sites when the largest ERN and Pe amplitudes were observed are presented in Figure 5.

An analysis of the ERN amplitudes revealed the main effects of group $(\mathrm{F}[1,48]=15.58, p<0.001)$ and electrode site $(F[11,528]=12.27, p<0.001)$. The $B D$ group exhibited significantly smaller ERN amplitudes than did the non-BD group. The largest ERN amplitude was observed at $\mathrm{Cz}(-3.65 \mu \mathrm{V})$ and the smallest amplitude at F4 $(-0.59$ $\mu \mathrm{V})$. In addition, an interaction effect of groupxelectrode site was observed $(F[11,528]=3.42, p<0.001)$. The BD group exhibited significantly smaller ERN amplitudes at $\mathrm{FCz}, \mathrm{C} 3, \mathrm{Cz}, \mathrm{C} 4, \mathrm{P} 3, \mathrm{Pz}$, and P4 than non-BD group. A main effect of electrode site was observed with respect to 
Table 3. Mean error-related negativity amplitudes and latencies in non-binge drinking and binge-drinking groups

\begin{tabular}{lcccc}
\hline \multirow{2}{*}{ Site } & \multicolumn{2}{c}{ Non-binge drinking $(\mathrm{n}=25)$} & \multicolumn{2}{c}{ Binge-drinking $(\mathrm{n}=25)$} \\
\cline { 2 - 3 } \cline { 4 - 4 } & Amplitude $(\mu \mathrm{V})$ & Latency $(\mathrm{ms})$ & Amplitude $(\mu \mathrm{V})$ & Latency $(\mathrm{ms})$ \\
\hline F3 & $-0.67 \pm 2.66$ & $58.72 \pm 18.37$ & $-0.79 \pm 2.75$ & $65.04 \pm 16.40$ \\
Fz & $-0.89 \pm 2.33$ & $56.00 \pm 17.36$ & $-0.98 \pm 2.42$ & $60.24 \pm 15.71$ \\
F4 & $-0.54 \pm 2.01$ & $60.64 \pm 17.35$ & $-0.64 \pm 2.43$ & $60.96 \pm 13.54$ \\
FC3 & $-2.04 \pm 1.82$ & $96.80 \pm 16.87$ & $-1.07 \pm 2.46$ & $96.08 \pm 17.42$ \\
FCz & $-3.88 \pm 1.84$ & $96.00 \pm 16.04$ & $-1.93 \pm 2.53$ & $95.84 \pm 15.43$ \\
FC4 & $-1.58 \pm 1.99$ & $94.24 \pm 16.71$ & $-0.67 \pm 2.21$ & $94.24 \pm 18.58$ \\
C3 & $-2.62 \pm 1.76$ & $94.80 \pm 16.50$ & $-1.04 \pm 1.96$ & $96.08 \pm 16.24$ \\
Cz & $-5.12 \pm 1.94$ & $92.24 \pm 15.31$ & $-2.18 \pm 2.60$ & $90.00 \pm 14.64$ \\
C4 & $-2.36 \pm 1.83$ & $94.56 \pm 15.65$ & $-0.59 \pm 1.33$ & $92.56 \pm 15.91$ \\
P3 & $-2.82 \pm 2.23$ & $94.64 \pm 13.20$ & $-1.19 \pm 1.89$ & $96.16 \pm 11.72$ \\
Pz & $-3.67 \pm 2.18$ & $96.16 \pm 14.14$ & $-1.55 \pm 1.76$ & $96.48 \pm 12.93$ \\
P4 & $-2.87 \pm 1.52$ & $96.64 \pm 14.24$ & $-1.17 \pm 1.39$ & $92.00 \pm 10.38$ \\
\hline
\end{tabular}

Values are presented as mean \pm standard deviation.

Table 4. Mean error positivity amplitudes and latencies in non-binge drinking and binge-drinking groups

\begin{tabular}{|c|c|c|c|c|}
\hline \multirow{2}{*}{ Site } & \multicolumn{2}{|c|}{ Non-binge drinking $(n=25)$} & \multicolumn{2}{|c|}{ Binge-drinking $(n=25)$} \\
\hline & Amplitude $(\mu \mathrm{V})$ & Latency (ms) & Amplitude $(\mu \mathrm{V})$ & Latency (ms) \\
\hline F3 & $0.27 \pm 2.93$ & $278.40 \pm 19.36$ & $0.13 \pm 2.68$ & $278.48 \pm 14.56$ \\
\hline $\mathrm{Fz}$ & $0.53 \pm 3.09$ & $283.28 \pm 20.39$ & $0.92 \pm 2.79$ & $285.36 \pm 19.68$ \\
\hline F4 & $0.92 \pm 3.13$ & $283.60 \pm 21.23$ & $0.80 \pm 2.82$ & $285.92 \pm 16.23$ \\
\hline $\mathrm{FC} 3$ & $1.38 \pm 2.46$ & $281.04 \pm 16.29$ & $0.61 \pm 2.02$ & $285.52 \pm 14.99$ \\
\hline $\mathrm{FCz}$ & $3.57 \pm 3.61$ & $280.00 \pm 17.14$ & $2.78 \pm 2.71$ & $286.00 \pm 17.97$ \\
\hline FC4 & $2.48 \pm 3.09$ & $279.64 \pm 19.67$ & $1.20 \pm 2.14$ & $286.72 \pm 17.41$ \\
\hline $\mathrm{C} 3$ & $1.89 \pm 3.01$ & $284.16 \pm 15.96$ & $0.47 \pm 2.09$ & $282.08 \pm 18.03$ \\
\hline $\mathrm{Cz}$ & $4.96 \pm 3.73$ & $281.60 \pm 22.12$ & $2.82 \pm 3.05$ & $277.12 \pm 20.01$ \\
\hline $\mathrm{C} 4$ & $2.33 \pm 2.78$ & $283.28 \pm 18.87$ & $1.14 \pm 1.87$ & $282.64 \pm 16.71$ \\
\hline P3 & $0.95 \pm 2.29$ & $279.92 \pm 20.72$ & $0.15 \pm 2.28$ & $283.20 \pm 16.58$ \\
\hline $\mathrm{Pz}$ & $0.39 \pm 2.84$ & $280.00 \pm 20.00$ & $0.32 \pm 2.73$ & $285.52 \pm 15.16$ \\
\hline P4 & $0.96 \pm 1.85$ & $280.48 \pm 18.64$ & $0.44 \pm 2.09$ & $285.76 \pm 17.93$ \\
\hline
\end{tabular}

Values are presented as mean \pm standard deviation.

ERN latency $(\mathrm{F}[11,528]=69.85, p<0.001)$. The shortest ERN latency was observed at Fz (58.12 ms), and the longest was observed at FC3 (96.44 ms). No significant main effect of group $(F[1,48]=0.02, n s)$ or interaction effect of groupxelectrode site $(F[11,528]=0.59$, ns) was observed. The mean ERN amplitudes and latencies for the BD and non-BD groups are presented in Table 3.

With regard to Pe amplitude, a main effect of electrode site was observed $(\mathrm{F}[11,528]=13.07, p<0.001)$. The Pe amplitude measured at $\mathrm{Cz}$ was the largest $(3.89 \mu \mathrm{V})$, and the smallest amplitude was at Fz $(0.20 \mu \mathrm{V})$. However, no significant main effect of group $(F[1,48]=3.02$, ns) or interaction effect of groupxelectrode site $(F[11,528]=1.08, n s)$ was observed. In terms of Pe latency, no significant main effect of group $(F[1,48]=0.80$, ns), electrode site $(F[11,528]=$
$0.65, \mathrm{~ns})$, or interaction effect of groupxelectrode site $(F[11,528]=0.60$, ns) was observed. The mean Pe amplitudes and latencies for the $\mathrm{BD}$ and non-BD groups are presented in Table 4.

\section{Correlations between ERN Amplitudes and BD Severity}

There were not any significant correlations between ERN amplitudes and scores on the AUDIT-K or AUQ in either BD group or non-BD group. However, significant correlations were detected between the total score on the AUDIT-K and the ERN amplitude measured at FCz $(\mathrm{r}=0.40, p<0.05)$ and $\mathrm{Cz}(\mathrm{r}=0.54, p<0.05)$ in the whole participants. In addition, significant correlations were observed between binge score on the AUQ and the ERN am- 
plitudes measured at $\mathrm{FCz}(\mathrm{r}=0.47, p<0.05)$ and $\mathrm{Cz}$ $(\mathrm{r}=0.40, p<0.05)$ in the whole sample. These results indicate that more $\mathrm{BD}$ leads to more reduced ERN amplitudes.

\section{DISCUSSION}

We used ERPs and the modified Flanker task to investigate whether female college students with $\mathrm{BD}$ had error-monitoring deficits. The BD group exhibited significantly more errors and shorter response times on the Flanker task compared with the non-BD group, indicating that individuals with $\mathrm{BD}$ have deficits in error-monitoring. The present findings are consistent with previous studies reporting higher error rates ${ }^{51)}$ and shorter response times $^{72-74)}$ in heavy drinkers compared with non-heavy drinkers. In the present study, the BD group showed more errors not only in the incongruent but also in the congruent conditions, which did not provide any response conflict compared with non-BD group. Higher error rates and faster response times in both conditions observed in individuals with $\mathrm{BD}$ seem to be related to the impulsivity these individuals have, since rapid response observed in heavy drinkers is related to the high level of impulsivity ${ }^{72)}$ and college students with BD show higher impulsivity than those with non-BD. ${ }^{75)}$ Unfortunately impulsivity was not assessed in this study.

The BD group showed significantly reduced ERN amplitudes than those in the non-BD group, consistent with previous findings. ${ }^{22,47,48)}$ For example, Ridderinkhof et al. ${ }^{44)}$ reported that normal controls who consume alcohol exhibit reduced ERN amplitudes than those who do not consume alcohol. In addition, Smith and Mattick ${ }^{22)}$ observed reduced ERN amplitudes in young female heavy drinkers than non-heavy drinkers.

Since ERN is known to reflect error detection ${ }^{42)}$ or the magnitude of an individual's responses to his/her own errors, ${ }^{38)}$ the reduced ERN amplitudes observed in the present study may indicate that individuals with BD have difficulties in monitoring their internal behavior. Previous studies have reported that the ACC is the generator of the ERN. ${ }^{39,76)}$ For example, Ullsperger and von Cramon ${ }^{19)}$ found that greater ACC activation is elicited after incorrect responses than correct responses, and O'Connell et al. ${ }^{77)}$ found that ERN is generated in the ACC by employing source localization analysis. Stemmer et al. ${ }^{78)}$ did not ob- serve ERN in patients with ACC lesions. In addition, reduced thickness of the ACC is observed in individuals with $\mathrm{BD}^{31)}$ and reduced $\mathrm{ACC}$ volume is observed in adolescent heavy drinkers. ${ }^{33)}$ These imaging studies support the interpretation that reduced ERN amplitudes observed in the present study indicate dysfunctional error-monitoring controlled mainly by ACC. In addition, total score on the AUDIT-K and the binge score on the AUQ were positively correlated with ERN amplitudes measures at $\mathrm{FCz}$ and $\mathrm{Cz}$. In other words, a greater amount and more frequent alcohol consumption are related to more reduced ERN amplitudes. All these findings indicate that observed smaller ERN amplitudes in individuals with BD are likely associated with structural abnormalities and dysfunctions in the ACC, which is involved in behavioral monitoring or inhibition.

Contrary to the present and previous findings, enhanced ERN amplitudes ${ }^{20)}$ or comparable ERN amplitudes ${ }^{511}$ were observed in young heavy drinkers compared with non-heavy drinkers. These inconsistent findings seem to result from differences in the tasks used to measure error-monitoring across studies. For example, Smith et al. ${ }^{51)}$ used the Go/NoGo task to measure error-monitoring and found no significant differences in ERN amplitudes between heavy drinkers and non-heavy drinkers. Although various tasks are used to evaluate error-monitoring, different results are produced depending on the tasks used. For example, Riesel et al..$^{79)}$ administered the Flanker, Stroop, and $\mathrm{Go} /$ NoGo tasks to measure error-monitoring ability in the same participants and found that the Stroop task produced more errors and smaller ERN amplitudes than the other two tasks. Inconsistent findings also seem to result from differences in participants' behavioral performance across studies. For example, Smith et al. ${ }^{20)}$ used the Flanker task to measure error-monitoring, and found enhanced ERN amplitudes in young female heavy drinkers. The authors suggested that enhanced ERN amplitudes reflect enhanced performance monitoring by heavy drinkers to achieve the same behavioral outcomes as the controls. In the present study, however, female college students with BD exhibited significantly more errors on the Flanker task compared with those with non-BD.

The BD and non-BD groups exhibited no significant differences in Pe amplitude and associations between Pe amplitudes and the scores on the AUDIT-K or AUQ were not observed. Previous studies with heavy drinkers re- 
ported inconsistent results regarding to Pe amplitudes. For example, some studies found no differences in Pe amplitudes between heavy drinkers and non-heavy drinkers, ${ }^{22,51)}$ whereas others observed smaller Pe amplitudes in heavy drinkers than non-heavy drinkers. ${ }^{49)}$ As Pe amplitude is larger for perceived errors than for unperceived errors, ${ }^{45,46)} \mathrm{Pe}$ is believed to reflect conscious error recognition. The comparable Pe amplitudes in the BD and non-BD groups indicate that college students with BD recognized their errors in the same way as those who did not participate in BD. Individuals who BD could perceive and recognize their erroneous responses, because the Flanker task which requires fast responding has the advantage of eliciting errors by slips rather than by mistakes resulting from misunderstanding the task. ${ }^{80)}$

This study had some limitations that should be addressed in future studies. First, only a small number of participants included in the present study limits generalizability of the findings. Second, to better understand the neurophysiological mechanisms of error-monitoring deficits experienced by individuals with BD, both neuroimaging techniques and ERPs should be used, because the structural abnormalities and dysfunctions in the ACC are observed in individuals with $\mathrm{BD}$ and those who drink heavily. Finally, BD college students are more likely to use other substances, including cigarettes and marijuana, ${ }^{81)}$ so these substances should be controlled for in future studies.

In conclusion, female BD college students exhibited significantly more errors and faster response times on the Flanker task and reduced ERN amplitude compared with those who did not participate in BD. Moreover, the ERN amplitudes measured at $\mathrm{FCz}$ and $\mathrm{Cz}$ were positively correlated with $\mathrm{BD}$ severity. These findings indicate that individuals with $\mathrm{BD}$ experience deficits in error-monitoring and self-control, and might give some explanations why individuals with BD continue alcohol consumption in spite of its associated negative consequences. Furthermore, present findings indicate that reduced ERN amplitudes may serve as a biological marker or risk factor for AUD. The present results also provide valuable information about detrimental effects of BD on cognitive and brain functions, even though the period of excessive alcohol consumption is relatively short (mean year of alcohol consumption in the BD group was 3.05 years).

\section{Acknowledgments}

This work was supported by the Ministry of Education of the Republic of Korea and the National Research Foundation of Korea (NRF-2015S1A5A2A03047656).

\section{REFERENCES}

1. Wechsler H, Nelson TF. Binge drinking and the American college student: what's five drinks? Psychol Addict Behav 2001; 15:287-291.

2. National Institute on Alcohol Abuse and Alcoholism (NIAAA). NIAAA council approves definition of binge drinking. NIAAA News/ 2004;(3):3.

3. O'Malley PM, Johnston LD. Epidemiology of alcohol and other drug use among American college students. J Stud A/Cohol Supp/ 2002;(14):23-39.

4. Wechsler H, Dowdall GW, Davenport A, Castillo S. Correlates of college student binge drinking. Am J Public Health 1995; 85:921-926.

5. Naimi TS, Brewer RD, Mokdad A, Denny C, Serdula MK, Marks JS. Binge drinking among US adults. JAMA 2003;289: 70-75.

6. Bonomo YA, Bowes G, Coffey C, Carlin JB, Patton GC. Teenage drinking and the onset of alcohol dependence: a cohort study over seven years. Addiction 2004;99:1520-1528.

7. Hill KG, White HR, Chung IJ, Hawkins JD, Catalano RF. Early adult outcomes of adolescent binge drinking: person- and variable-centered analyses of binge drinking trajectories. Alcohol Clin Exp Res 2000;24:892-901.

8. Mota N, Parada M, Crego A, Doallo S, Caamaño-lsorna F, Rodríguez Holguín S, et al. Binge drinking trajectory and neuropsychological functioning among university students: a longitudinal study. Drug A/cohol Depend 2013;133:108-114.

9. Thayanukulvat $\mathrm{C}$, Harding T. Binge drinking and cognitive impairment in young people. Br J Nurs 2015;24:401-407.

10. Courtney KE, Polich J. Binge drinking in young adults: data, definitions, and determinants. Psychol Bull 2009;135:142156.

11. Petit G, Kornreich C, Verbanck P, Campanella S. Gender differences in reactivity to alcohol cues in binge drinkers: a preliminary assessment of event-related potentials. Psychiatry Res 2013;209:494-503.

12. Crego A, Holguín SR, Parada M, Mota N, Corral M, Cadaveira F. Binge drinking affects attentional and visual working memory processing in young university students. Alcohol Clin Exp Res 2009;33:1870-1879.

13. Parada M, Corral M, Mota N, Crego A, Rodríguez Holguín S, Cadaveira F. Executive functioning and alcohol binge drinking in university students. Addict Behav 2012;37:167-172.

14. Hartley DE, Elsabagh S, File SE. Binge drinking and sex: effects on mood and cognitive function in healthy young volunteers. Pharmacol Biochem Behav 2004;78:611-619. 
15. Ames SL, Wong SW, Bechara A, Cappelli C, Dust M, Grenard JL, et al. Neural correlates of a Go/NoGo task with alcohol stimuli in light and heavy young drinkers. Behav Brain Res 2014;274:382-389.

16. Franken $\mathrm{IH}$, van de Wetering BJ. Bridging the gap between the neurocognitive lab and the addiction clinic. Addict Behav 2015;44:108-114.

17. Luijten M, Machielsen MW, Veltman DJ, Hester R, de Haan L, Franken IH. Systematic review of ERP and fMRI studies investigating inhibitory control and error processing in people with substance dependence and behavioural addictions. I Psychiatry Neurosci 2014;39:149-169.

18. Ganushchak LY, Schiller NO. Effects of time pressure on verbal self-monitoring: an ERP study. Brain Res 2006;1125:104115.

19. Ullsperger M, von Cramon DY. Neuroimaging of performance monitoring: error detection and beyond. Cortex 2004; 40:593-604.

20. Smith JL, Mattick RP, Sufani C. Female but not male young heavy drinkers display altered performance monitoring. Psychiatry Res 2015;233:424-435.

21. Fein G, Chang M. Smaller feedback ERN amplitudes during the BART are associated with a greater family history density of alcohol problems in treatment-naive alcoholics. Drug A/cohol Depend 2008;92:141-148.

22. Smith JL, Mattick RP. Evidence of deficits in behavioural inhibition and performance monitoring in young female heavy drinkers. Drug A/cohol Depend 2013;133:398-404.

23. Smith JL, Iredale JM, Mattick RP. Sex differences in the relationship between heavy alcohol use, inhibition and performance monitoring: Disconnect between behavioural and brain functional measures. Psychiatry Res 2016;254:103-111.

24. Brown JW, Braver TS. Learned predictions of error likelihood in the anterior cingulate cortex. Science 2005;307:11181121.

25. Kim C, Chung C, Kim J. Task-dependent response conflict monitoring and cognitive control in anterior cingulate and dorsolateral prefrontal cortices. Brain Res 2013;1537:216223.

26. Dirksen CL, Howard JA, Cronin-Golomb A, Oscar-Berman M. Patterns of prefrontal dysfunction in alcoholics with and without Korsakoff's syndrome, patients with Parkinson's disease, and patients with rupture and repair of the anterior communicating artery. Neuropsychiatr Dis Treat 2006;2:327-339.

27. Oscar-Berman M, Hutner N. Frontal lobe changes after chronic alcohol ingestion. In: Hunt WA, Nixon SJ, editors. Alcohol-induced brain damage (NIAAA Research Monograph No 22). Rockville:US Department of Health and Human Services, NIH Publication; 1993. p.121-156.

28. Ratti MT, Bo P, Giardini A, Soragna D. Chronic alcoholism and the frontal lobe: which executive functions are imparied? Acta Neurol Scand 2002;105:276-281.

29. Pfefferbaum A, Sullivan EV, Mathalon DH, Lim KO. Frontal lobe volume loss observed with magnetic resonance imaging in older chronic alcoholics. Alcohol Clin Exp Res 1997;21: 521-529.

30. Gansler DA, Harris GJ, Oscar-Berman M, Streeter C, Lewis RF, Ahmed I, et al. Hypoperfusion of inferior frontal brain regions in abstinent alcoholics: a pilot SPECT study. I Stud A/cohol 2000;61:32-37.

31. Mashhoon Y, Czerkawski C, Crowley DJ, Cohen-Gilbert JE, Sneider JT, Silveri MM. Binge alcohol consumption in emerging adults: anterior cingulate cortical "thinness" is associated with alcohol use patterns. Alcohol Clin Exp Res 2014;38: 1955-1964.

32. Crego A, Rodriguez-Holguín S, Parada M, Mota N, Corral M, Cadaveira F. Reduced anterior prefrontal cortex activation in young binge drinkers during a visual working memory task. Drug A/cohol Depend 2010;109:45-56.

33. Squeglia LM, Jacobus J, Tapert SF. The effect of alcohol use on human adolescent brain structures and systems. Handb Clin Neurol 2014;125:501-510.

34. Luck SJ, Woodman GF, Vogel EK. Event-related potential studies of attention. Trends Cogn Sci 2000:4:432-440.

35. Hajcak G, Moser JS, Yeung N, Simons RF. On the ERN and the significance of errors. Psychophysiology 2005;42:151-160.

36. Van Veen V, Carter CS. The timing of action-monitoring processes in the anterior cingulate cortex. J Cogn Neurosci 2002; 14:593-602.

37. Falkenstein M, Hohnsbein J, Hoormann J, Blanke L. Effects of errors in choice reaction tasks on the ERP under focused and divided attention. In: Brunia CHM, Gaillard AWK, Kok A, editors. Psychophysiological brain research. Tilburg:Tilburg University Press;1990. p. 192-195.

38. Gehring WJ, Goss B, Coles MGH, Meyer DE, Donchin E. A neural system for error detection and compensation. Psychol Sci 1993;4:385-390.

39. Herrmann MJ, Römmler J, Ehlis AC, Heidrich A, Fallgatter AJ. Source localization (LORETA) of the error-related-negativity (ERN/Ne) and positivity (Pe). Brain Res Cogn Brain Res 2004; 20:294-299.

40. Kim SH, Jang KM, Kim MS. Deficits in error-monitoring by college students with schizotypal traits: an event-related potential study. PLoS One 2015;10:e0122861.

41. Overbeek TJM, Nieuwenhuis S, Ridderinkhof KR. Dissociable components of error processing. J Psychophysiol 2005;19: 319-329.

42. Falkenstein M, Hoormann J, Christ S, Hohnsbein J. ERP components on reaction errors and their functional significance: a tutorial. Biol Psychol 2000;51:87-107.

43. Wessel JR. Error awareness and the error-related negativity: evaluating the first decade of evidence. Front Hum NeurosCi 2012;6:88.

44. Ridderinkhof $\mathrm{KR}$, de Vlugt $\mathrm{Y}$, Bramlage $\mathrm{A}$, Spaan $\mathrm{M}$, Elton $\mathrm{M}$, Snel J, et al. Alcohol consumption impairs detection of performance errors in mediofrontal cortex. Science 2002;298: 
2209-2211.

45. Endrass T, Franke C, Kathmann N. Error awareness in a saccade countermanding task. J Psychophysiol 2005;19:275280.

46. Nieuwenhuis S, Ridderinkhof KR, Blom J, Band GP, Kok A. Error-related brain potentials are differentially related to awareness of response errors: evidence from an antisaccade task. Psychophysiology 2001;38:752-760.

47. Bartholow BD, Henry EA, Lust SA, Saults JS, Wood PK. Alcohol effects on performance monitoring and adjustment: affect modulation and impairment of evaluative cognitive control. J Abnorm Psychol 2012;121:173-186.

48. Easdon C, Izenberg A, Armilio ML, Yu H, Alain C. A/cohol consumption impairs stimulus- and error-related processing during a Go/No-Go Task. Brain Res Cogn Brain Res 2005;25. 873-883.

49. Franken IHA, Luijten $M$, van der Veen FM, van Strien JW. Cognitive control in young heavy drinkers: An ERP study. Drug A/cohol Depend 2017;175:77-83.

50. Schellekens AF, de Bruijn ER, van Lankveld CA, Hulstijn W, Buitelaar JK, de Jong CA, et al. A/cohol dependence and anxiety increase error-related brain activity. Addiction 2010;105: 1928-1934.

51. Smith JL, Mattick RP, Sufani C. Error detection and behavioural inhibition in young heavy drinkers. Drug Alcohol Depend 2017;171:20-30.

52. Eriksen BA, Eriksen CW. Effects of noise letters upon the identification of a target letter in a nonsearch task. Percept Psychophys 1974;16:143-149.

53. Kopp B, Rist F, Mattler U. N200 in the flanker task as a neurobehavioral tool for investigating executive control. Psychophysiology 1996;33:282-294.

54. Botvinick MM, Cohen JD, Carter CS. Conflict monitoring and anterior cingulate cortex: an update. Trends Cogn Sci 2004;8: 539-546.

55. Lehle C, Hübner R. On-the-fly adaptation of selectivity in the flanker task. Psychon Bull Rev 2008;15:814-818.

56. Marinkovic K, Rickenbacher E, Azma S. Effects of alcohol intoxication on response conflict in a flanker task. J Addict Res Ther 2012; Supp/ 3:002.

57. Nolen-Hoeksema S. Gender differences in risk factors and consequences for alcohol use and problems. Clin Psychol Rev 2004;24:981-1010.

58. Weafer J, De Arcangelis J, de Wit H. Sex differences in behavioral impulsivity in at-risk and non-risk drinkers. Front Psychiatry 2015;6:72.

59. Babor TF, Higgins-Biddle JC, Saunders JB, Monteiro MG. AUDIT: the Alcohol Use Disorders Identification Test (AUDIT): guidelines for use in primary care. 2nd ed. Geneva: World Health Organization;2001.

60. Lee BO, Lee $\mathrm{CH}$, Lee PG, Choi MJ, Namkoong K. Development of Korean version of Alcohol Use Disorders Identification Test (AUDIT-K): its reliability and validity. J
Korean Acad Addiction Psychiatry 2000;4:83-92.

61. Mehrabian A, Russell JA. A questionnaire measure of habitual alcohol use. Psychol Rep 1978:43:803-806.

62. Kim JS, Oh MK, Park BK, Lee MK, Kim GJ. Screening criteria of alcoholism by Alcohol Use Disorders Identification Test (AUDIT) in Korea. J Korean Acad Fam Med 1999;20:11521159.

63. First MB, Spitzer RL, Gibbson M, Williams JBW. User's guide for the Structured Clinical Interview for DSM-IV Axis I Disorders: SCID-1 clinician version. New York:New York State Psychiatric Institute; 1996.

64. Ary DV, Tildesley E, Hops $\mathrm{H}$, Andrews J. The influence of parent, sibling, and peer modeling and attitudes on adolescent use of alcohol. Int J Addict 1993;28:853-880.

65. Jones JW. The children of alcoholics screening test: test manual. Chicago:Camelot Unlimited;1983.

66. Yum TH, Park YS, Oh KJ, Kim JG, Lee YH. The manual of Korean-Wechsler Adult Intelligence Scale. Seoul:Korea Guidance; 1992.

67. Zung WW, Richards CB, Short MJ. Self-rating depression scale in an outpatient clinic. Further validation of the SDS. Arch Gen Psychiatry 1965; 13:508-515.

68. Spielberger CD, Gorauch RL, Lushene RE. Manual for the State-Trait Anxiety Inventory. Palo Alto, CA:Consulting Psychologists Press; 1970.

69. Townshend JM, Duka T. Patterns of alcohol drinking in a population of young social drinkers: a comparison of questionnaire and diary measures. Alcohol A/cohol 2002;37: 187-192.

70. lannaccone R, Hauser TU, Staempfli P, Walitza S, Brandeis D, Brem S. Conflict monitoring and error processing: new insights from simultaneous EEG-fMRI. Neuroimage 2015;105: 395-407.

71. Tucker DM. Spatial sampling of head electrical fields: the geodesic sensor net. Electroencephalogr Clin Neurophysiol 1993;87:154-163.

72. Henges AL, Marczinski CA. Impulsivity and alcohol consumption in young social drinkers. Addict Behav 2012;37: 217-120.

73. Kreusch F, Vilenne A, Quertemont E. Response inhibition toward alcohol-related cues using an alcohol go/no-go task in problem and non-problem drinkers. Addict Behav 2013;38: 2520-2528.

74. Townshend JM, Duka T. Binge drinking, cognitive performance and mood in a population of young social drinkers. A/cohol Clin Exp Res 2005;29:317-325.

75. Adan A, Navarro JF, Forero DA. Personality profile of binge drinking in university students is modulated by sex. A study using the Alternative Five Factor Model. Drug A/cohol Depend 2016;165:120-125.

76. Hester R, Garavan H. Executive dysfunction in cocaine addiction: evidence for discordant frontal, cingulate, and cerebellar activity. J Neurosci 2004;24:11017-11022. 
77. O’Connell RG, Bellgrove MA, Dockree PM, Lau A, Hester R, Garavan $\mathrm{H}$, et al. The neural correlates of deficient error awareness in attention-deficit hyperactivity disorder (ADHD). Neuropsychologia 2009:47:1149-1159.

78. Stemmer B, Segalowitz SJ, Witzke W, Schönle PW. Error detection in patients with lesions to the medial prefrontal cortex: an ERP study. Neuropsychologia 2004;42:118-130.

79. Riesel A, Weinberg A, Endrass T, Meyer A, Hajcak G. The ERN is the ERN is the ERN? Convergent validity of error-related brain activity across different tasks. Biol Psychol 2013;93: 377-385.

80. Pailing PE, Segalowitz SJ, Dywan J, Davies PL. Error negativity and response control. Psychophysiology 2002;39:198-206.

81. Jones SE, Oeltmann J, Wilson TW, Brener ND, Hill CV. Binge drinking among undergraduate college students in the United States: implications for other substance use. J Am Coll Health 2001; 50:33-38 